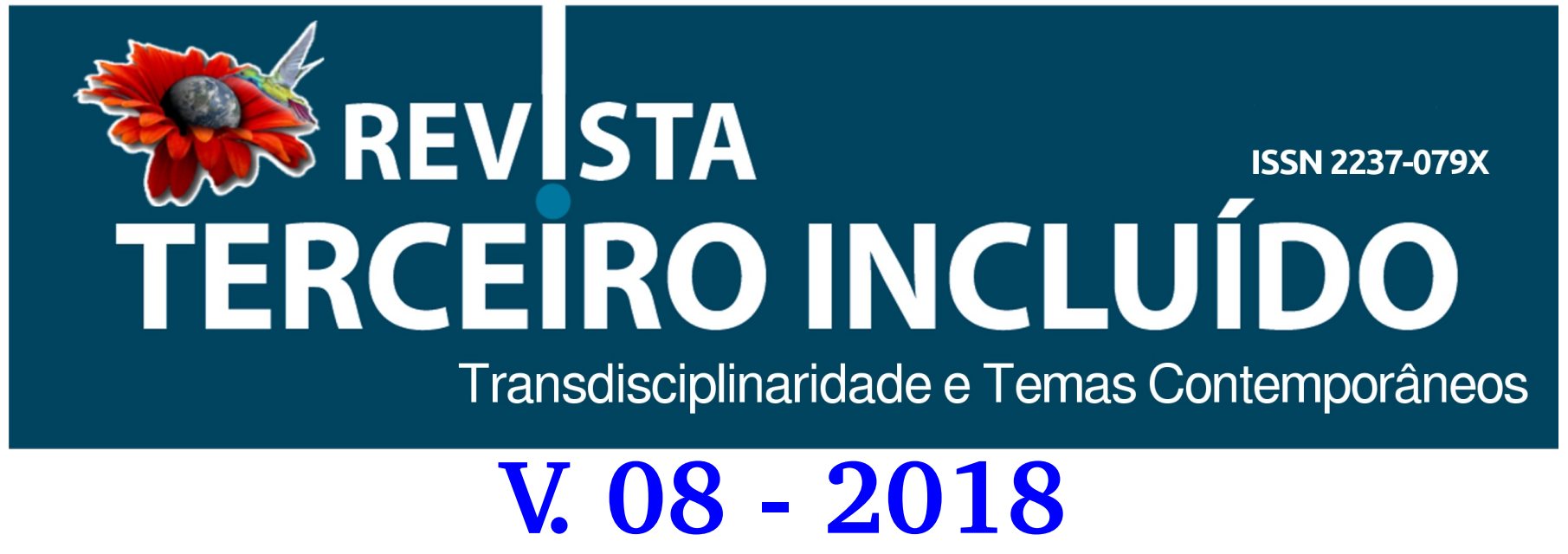

ÁVILA, Adriana Sousa Nascimento; FERNANDES, Leonardo Botosso; CARNEIRO, Vandervilson Alves.

Impactos Ambientais Em Nascente Urbana: Estudo De Um Trecho Do Córrego Catingueiro Em Anápolis-GO

pp. 27-39

DOI: $10.5216 /$ teri.v8i1.51100 


\title{
IMPACTOS AMBIENTAIS EM NASCENTE URBANA: ESTUDO DE UM TRECHO DO CORREGO CATINGUEIRO EM ANAPOLIS-GO
}

\section{ENVIRONMENTAL IMPACTS ON URBAN NASCENT:STUDY OF A STRETCH OF THE CATINGUEIRO STREAM IN ANAPPOLIS-GO}

\section{IMPACTOS AMBIENTALES EN NACIENTE URBANA: ESTUDIO DE UN SECTOR DEL RIACHUELO CATINGUEIRO EN ANAPOLIS-GO}

\author{
Adriana Sousa Nascimento ÁVILA ${ }^{1}$ \\ Leonardo Botosso FERNANDES ${ }^{2}$ \\ Vandervilson Alves CARNEIRO ${ }^{3}$
}

RESUMO: Com o aumento da população urbana no Brasil verifica-se um crescimento nas demandas hídricas, repercutindo na degradação dos mananciais. No caso específico de Anápolis, o crescimento desordenado do sitio urbano evidenciou a problemática da ocupação irregular em áreas de nascentes. Esse é o caso do córrego Catingueiro, que está localizado na região oeste da cidade. A expansão da cidade nas cabeceiras deste córrego afetou diretamente a qualidade hídrica desse manancial, sendo as consequências ainda mais preocupantes, pois o mesmo é um dos principais afluentes da bacia do Ribeirão João Leite que é o manancial responsável pelo abastecimento público da Região Metropolitana de Goiânia. Buscou-se com essa pesquisa avaliar as condições ambientais de um trecho na sub-bacia do córrego Catingueiro a fim de identificar os impactos ambientais negativos e sua relação com a expansão urbana, bem como, verificar as mudanças ocorridas ao longo desses anos através da comparação com os estudos prévios. Os procedimentos para o desenvolvimento desse estudo foram vistorias in loco, no trecho do córrego Catingueiro, a fim de verificar a situação atual das nascentes, evidenciarem os principais impactos ambientais, realizar o registro fotográfico e entrevista informal com os moradores do local. Também foi necessário levantamento bibliográfico em livros e artigos científicos, para estabelecer as definições e conceitos relacionados ao trabalho e apresentar as discussões pertinentes ao tema proposto. Verificou-se que a área de estudo continua bastante degradada e que os impactos socioambientais, como nascentes aterradas, sulcos e ravinas, ausência de mata ciliar entre outros, ainda estão presentes na atualidade, no entanto, em alguns locais houve revitalização da mata ciliar bem como se constatou uma maior exigência dos órgãos públicos em renovar licenças ambientais para as indústrias de extração de argila na APA (Área de Proteção Ambiental) do Ribeirão João Leite.

Palavras - chave: Impactos Ambientais. Nascentes. Meio Urbano. Anápolis. Córrego Catingueiro.

ABSTRACT: In Brazil with rising rates of urban population larger water demands have arisen, although this was followed by the watersheds degradation. In Anápolis Municipality, the disordered use and occupation of the soil in the urban site have displayed the problematic irregular expansion in water springs areas. This is the history of the Catingueiro stream, which is located in the western region of the Anápolis city. The expansion of that city near the stream headwaters, directly have affected the water quality of this source, and the main consequences are even more worrisome, since it is one of the main tributaries of the João Leite basin, which is the main public source of supply in the metropolitan region of Goiania City. The main objective of this research was to evaluate the environmental conditions of a stretch in the Catingueiro stream sub-basin in order to identify negative environmental impacts and their relationship with urban growth, to verify the changes that have occurred over those years through the comparison with the previous study. The procedures for the development of this study were surveys in the stretch of the Catingueiro stream to verify the current situation of the water springs to find the main environmental impacts, to make the photographic record and informal interview with the local residents. A bibliographical research also was made in books and scientific papers to generate definitions and concepts on the subject. It was found that the region surveyed remains very degraded and that the social and environmental impacts reported previously remain in present today, but in some regions there was revitalization of native vegetation and there was a greater requirement of the government to renew environmental licenses for the clay factories extraction in the EPA (Environmental Protection Area) of stream João Leite.

Keywords: Environmental Impacts. Springs. Urban medium. Anápolis. Catingueiro stream.

RESUMEN: Con el aumento de la población urbana en Brasil se verifica un crecimiento en las demandas hídricas, repercutiendo en la degradación de los manantiales. En el caso específico de Anápolis, el crecimiento desordenado del sitio urbano evidenció la problemática de la ocupación irregular en áreas de manantiales. Este es el caso del arroyo Catingueiro, que se encuentra en el oeste de la ciudad. La expansión de la ciudad en las cabeceras de este arroyo afectó directamente la calidad hídrica de ese manantial, siendo las

1 Pós-Graduanda do Curso de Engenharias, Tecnologias e Sustentabilidade Urbana / UEG - Universidade Estadual de Goiás, Campus Henrique Santillo (Anápolis / Go). Email: adrianadrigeo@gmail.com

2 Pós-Graduando do Curso de Engenharias, Tecnologias e Sustentabilidade Urbana / UEG - Universidade Estadual de Goiás, Campus Henrique Santillo (Anápolis / GO). Email: leonardobotosso@gmail.com

3 Docente do Curso de Pós-Graduação Lato Sensu em Engenharias, Tecnologias e Sustentabilidade Urbana / UEG - Universidade Estadual de Goiás, Campus Henrique Santillo (Anápolis / GO). Email: profvandervilson@hotmail.com 
consecuencias aún más preocupantes, pues el mismo es uno de los principales afluentes de la cuenca del Ribeirão João Leite que es el manantial responsable del abastecimiento público de la Región Metropolitana de Goiânia. Se buscó con esa investigación evaluar las condiciones ambientales de un tramo en la subcuenca del riachuelo Catingueiro a fin de identificar los impactos ambientales negativos y su relación con la expansión urbana, así como, verificar los cambios ocurridos a lo largo de esos años a través de la comparación con los estudios previos. Los procedimientos para el desarrollo de este estudio fueron inspecciones in situ, en el tramo del riachuelo Catingueiro, a fin de verificar la situación actual de los manantiales, evidenciar los principales impactos ambientales, realizar el registro fotográfico y entrevista informal con los habitantes del local. También fue necesario un levantamiento bibliográfico en libros y artículos científicos, para establecer las definiciones y conceptos relacionados al trabajo y presentar las discusiones pertinentes al tema propuesto. Se verificó que el área de estudio continúa bastante degradada y que los impactos socioambientales, como nacientes aterrizados, surcos y ravinas, ausencia de mata ciliar entre otros, todavía están presentes en la actualidad, sin embargo, en algunos locales hubo revitalización de la mata ciliar bien como se constató una mayor exigencia de los organismos públicos en renovar licencias ambientales para las industrias de extracción de arcilla en la APA (Área de Protección Ambiental) del Ribeirão João Leite.

Palabras-clave: Impactos ambientales. Manantiales. Medio Urbano. Anápolis. Riachuelo Catingueiro.

\section{INTRODUÇÃO}

O grande problema ambiental do século XXI é a escassez de água, visto que as atividades humanas têm prejudicado a qualidade de água, sobretudo da água superficial, que é receptor de todo tipo de poluente (MATOS, 2010). No seu percurso em áreas urbanas, os rios recebem uma carga de poluentes de grandes proporções que causam alterações na qualidade, na biota, na morfologia e no regime hidrológico do rio (POLETO et al., 2010).

A maior parte das cidades no Brasil não possui tratamento de esgoto e lança os dejetos na rede de esgotamento pluvial, não programam as redes de drenagem urbana ocasionando inundações e alagamentos, e além do aumento da carga de resíduos sólidos que afetam a quantidade e a qualidade da água (TUCCI, 2008).

Para Tundisi (2008) torna-se fundamental, promover, em âmbito nacional, um conjunto de estudos estratégicos sobre recursos hídricos e energia, recursos hídricos e economia, água e saúde humana, água e mudanças globais climáticas e de biodiversidade, com a finalidade de promover visões e cenários de longo prazo que estimulem políticas públicas consolidadas.

No caso específico de Anápolis, localizada entre a capital federal (Brasília) e a capital do Estado de Goiás (Goiânia), o uso desordenado do solo no sítio urbano evidencia a problemática da ocupação irregular das nascentes. Esse é o caso do Córrego Catingueiro, que está localizado na área oeste da cidade. A expansão da cidade nas cabeceiras deste córrego gera impactos diretos sobre esse manancial, com consequências preocupantes, pois o mesmo é um dos principais afluentes da bacia do Ribeirão João Leite, que é o abastecedouro de boa parte da capital goiana.

Buscou-se com essa pesquisa avaliar as condições ambientais de um trecho na sub-bacia do Córrego Catingueiro, a fim de identificar os impactos ambientais e sua relação com a expansão urbana, bem como, verificar as mudanças ocorridas ao longo dos anos de 2003 a 2017 por meio da comparação com o estudo apresentado por Nascimento (2003).

Dessa maneira, tornam-se relevantes pesquisas e levantamentos de impactos ambientais nessa área, devido sua grande importância para o município de Anápolis e para a sociedade em geral, sendo esse estudo um instrumento importante para a intervenção da comunidade e do poder público nesse ambiente. 
O estudo foi desenvolvido num trecho do Córrego Catingueiro, situado na porção oeste da zona urbana do município de Anápolis / GO (figura 1). A área de estudo foi escolhida em função do grande número de impactos destacados pelo estudo desenvolvido por Nascimento (2003), e também pela ausência de mata ciliar, trechos assoreados, zonas de entulho, processos erosivos lineares, extrativismo de argilas, entre outros. Dessa maneira, buscou-se verificar durante esse período se houve melhoria nos locais ou se o processo de degradação foi acentuado.

Figura 1 - Localização de Anápolis e do Córrego Catingueiro

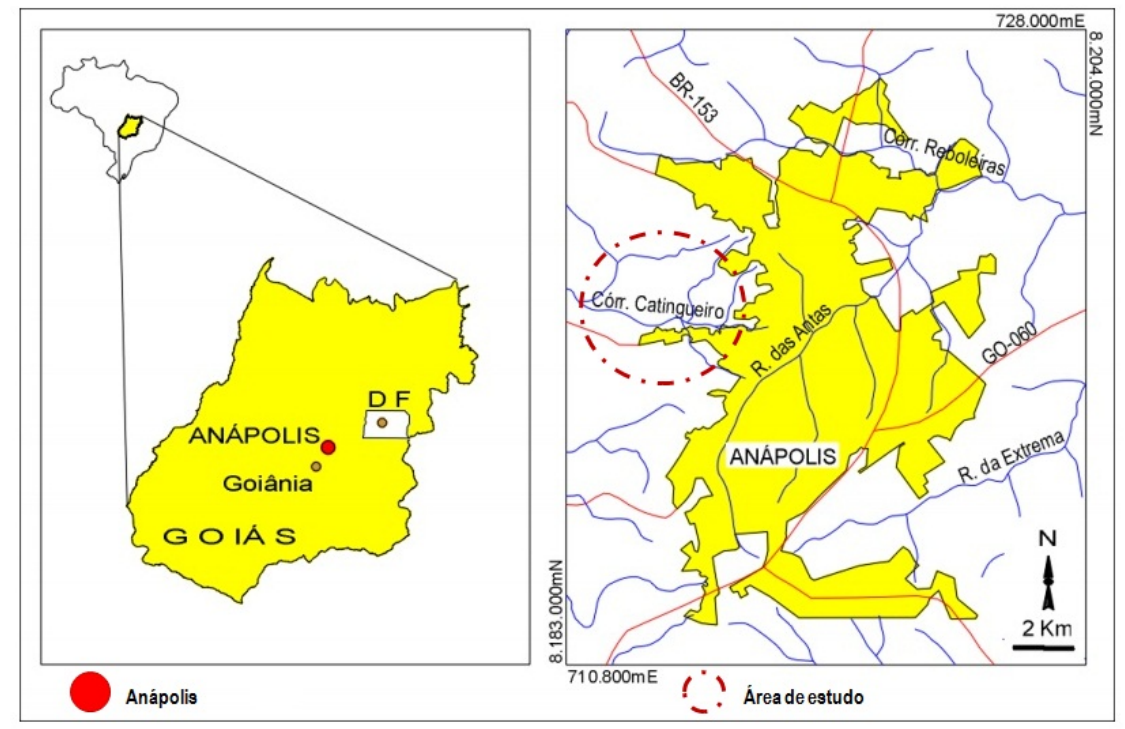

Fonte: LACERDA (2005), ajustes realizados pelos autores em 2018

Os procedimentos para o desenvolvimento desse estudo contou com vistorias in loco nos dias 30 de junho e 15 de agosto de 2017, em trechos do Córrego Catingueiro, a fim de verificar a situação atual das nascentes, evidenciando os principais impactos ambientais, além de realizar o registro fotográfico e anotações em caderneta de campo para subsidiar o texto final. Também foi necessária a captura de imagens do Google Earth, além de "garimpo" de textos acadêmicos (artigos, dissertações, teses e outros) com pertinência para fundamentar os apontamentos in situ e às discussões posteriores (figura 2).

Figura 2 - Trecho percorrido do Córrego Catingueiro

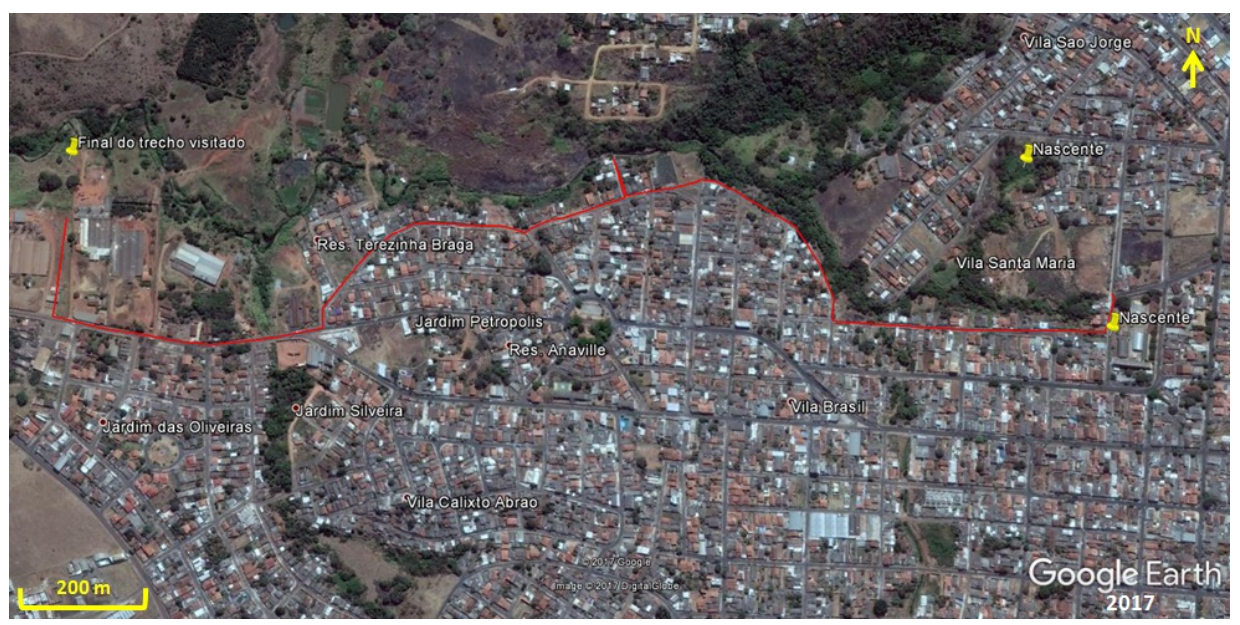

Fonte: Google Earth (2017), inserções feitas pelos autores em 2017 
Para analisar e checar os tipos de impactos ambientais foram percorridos 2,3 km a pé, ao longo do Córrego Catingueiro, de montante à jusante, em trechos localizados da Vila Santa Maria até a Vila Fabril.

\title{
RESULTADOS E DISCUSSÃO
}

Foram encontrados diversos problemas ao longo do trecho como ocupação inadequada de áreas de preservação, impermeabilização, contaminação do corpo hídrico, crescimento da ocupação de forma bem acentuada, erosões e deposição irregular de resíduos diversos.

Anápolis teve seu crescimento impulsionado pela ferrovia, o que abriu novas perspectivas de desenvolvimento. No entanto, não houve a compatibilidade entre os recursos e os usos, ou seja, o dinamismo causado pelas atividades humanas no espaço urbano resultou em um crescimento desordenado, causando danos ao meio ambiente.

\begin{abstract}
Os bairros situados nas áreas a montante do córrego Catingueiro foram se expandindo em direção às nascentes de forma totalmente adversa, ou seja, não houve a preocupação na adoção de uma infraestrutura adequada que conciliasse a inclusão de projetos de arruamentos, construção de terraplenagem, drenagem da rede pluvial, saneamento com as particularidades físicas do local, topografia, solo, declividade, área de proteção ambiental (NASCIMENTO, 2003, p.101).
\end{abstract}

Percebe-se no quadro 1 que, os bairros considerados, são antigos e legalizados pelo poder público, apesar de possuírem as margens do córrego faixas decretadas como áreas de proteção ambiental conforme legislação vigente no plano diretor da cidade de Anápolis Lei Complementar № 001 de 15 de Fevereiro de 2016 e do Capítulo II das Áreas de Preservação Permanente prevista na Lei nº 12.651 de 25 de março de 2012 do Novo Código Florestal.

\section{Quadro 1 - Bairros localizados na área de estudo}

\begin{tabular}{|l|c|c|}
\hline NOME DO LOTEAMENTO & DECRETO/PORTARIA & DATA DE APROVAÇÃO \\
\hline Vila F abril & Port. 115 & $31 / 10 / 1951$ \\
\hline Vila Brasil & Port. 048 & $21 / 05 / 1955$ \\
\hline Vila Santa Maria & Port. 209 & $27 / 12 / 1961$ \\
\hline Jardim Petrópolis & Port. 061 & $22 / 07 / 1969$ \\
\hline Residencial Terezinha Braga & Dec. 5892 & $30 / 12 / 1994$ \\
\hline
\end{tabular}

Fonte: Nascimento (2003), adaptado pelos autores (2017)

O plano diretor da cidade de Anápolis (2016) define-se os seguintes parâmetros para estabelecer como área de proteção ambiental:

Para as Áreas de Preservação Permanente - APP serão considerados os seguintes critérios: I. As faixas marginais de qualquer curso d'água natural perene e intermitente, excluídos os efêmeros, desde a borda da calha do leito regular, em largura mínima de: a) 30,00m (trinta metros) para os cursos d'água de menos de 10,00m (dez metros) de largura; b) 50,00m (cinquenta) metros para os cursos d'água que tenham mais de $10,00 \mathrm{~m}$ (dez) de largura.

$\$ 3^{\circ}$. As áreas no entorno das nascentes ainda que intermitentes e nos chamados olhos d'água, qualquer que seja a sua situação topográfica, num raio mínimo de 50,00m (cinquenta) metros em projeção horizontal.

No âmbito da legislação federal, verifica-se, na Lei no 12.651 de 25 de março de 2012 do 
Seção I.

Da Delimitação das Áreas de Preservação Permanente

Art. 4o Considera-se Área de Preservação Permanente, em zonas rurais ou urbanas, para os efeitos desta Lei:

I - as faixas marginais de qualquer curso d'água natural perene e intermitente, excluídos os efêmeros, desde a borda da calha do leito regular, em largura mínima de:

a) 30 (trinta) metros, para os cursos d'água de menos de 10 (dez) metros de largura;

b) 50 (cinquenta) metros, para os cursos d'água que tenham de 10 (dez) a 50 (cinquenta) metros de largura;

c) 100 (cem) metros, para os cursos d'água que tenham de 50 (cinquenta) a 200 (duzentos) metros de largura;

d) 200 (duzentos) metros, para os cursos d'água que tenham de 200 (duzentos) a 600 (seiscentos) metros de largura;

e) 500 (quinhentos) metros, para os cursos d'água que tenham largura superior a 600 (seiscentos) metros;

De acordo com o Plano Diretor de Anápolis (2016) e do novo Código Florestal (2012), as áreas de nascentes, sejam elas perenes ou intermitentes, em perímetro urbano ou rural, devem ter um raio mínimo de 50 metros. Tal faixa é necessária para garantir a proteção e a integridade do local onde nasce à água e para manter a sua qualidade e quantidade, visto que são essenciais para a garantia do sistema hídrico.

\begin{abstract}
A emergência da questão de proteção das nascentes está particularmente presente em espaços urbanos. A legislação específica para a maior parte das zonas urbanas brasileiras não garantiu, em termos ambientais, a necessária proteção das nascentes ao longo do tempo, em parte devido à falta de operacionalização do aparato legal e também devido aos diversos interesses especulativos e imobiliários do espaço urbano. Para a construção de residências, prédios comerciais, ou mesmo da infraestrutura urbana, muitas nascentes foram drenadas e, portanto, destruídas (FELIPPE, 2017 p. 9).
\end{abstract}

Nesse quesito, a mata ciliar é responsável pela proteção dos cursos d'água de qualquer tipo (MARTINS, 2014). Verifica-se na figura 3, a expansão urbana às margens do curso fluvial, acarretando em supressão da vegetação, conforme destacado em vermelho. No entanto, em alguns trechos, marcado em verde, percebe-se que na margem direita ocorreu supressão vegetal, já na margem esquerda mantém-se o cordão de vegetação ciliar.

Figura 3 - Trechos observados do Córrego Catingueiro em domínio ciliar

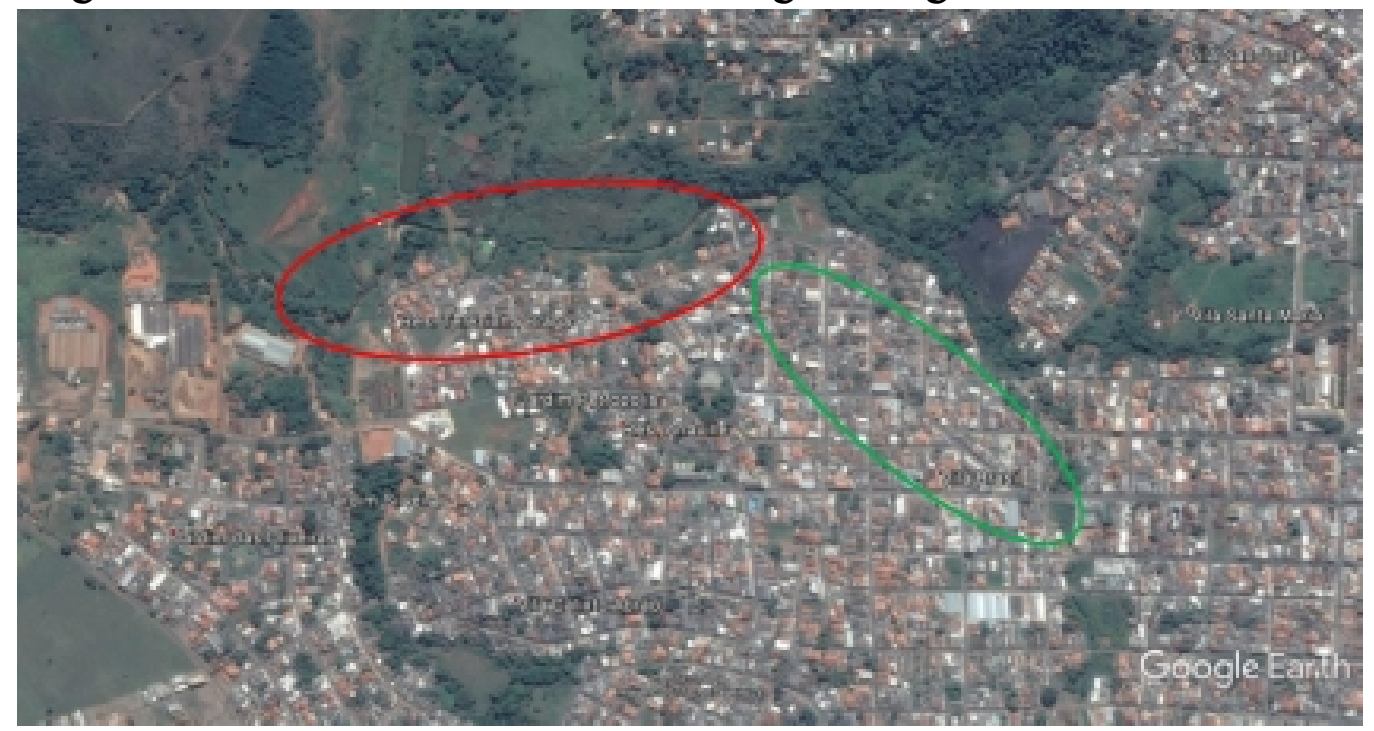


Nogueira et al. (2016) relatam que a pressão antrópica na maioria das vezes, é gerada pela ausência de planejamento, o que acarreta em ocupação desordenada e irregular do ambiente urbano, além de exercer grande impacto sobre os recursos naturais, provocando, adicionalmente, riscos à vida da população residente nestes espaços.

Cabe relatar que a supressão da vegetação ciliar associada à concentração dos fluxos que drenam para essas áreas, acentuou a ação erosiva e o grande aporte de sedimentos lançados ao sistema fluvial local.

As particularidades físicas da região apresentam um forte potencial para a ocorrência de erosão, em que a água desempenha um papel primordial aliada a elevada declividade e as características dos solos. Essa configuração natural não oferece muita resistência à interferência antrópica, sendo essa atuação humana fator multiplicadora dos impactos negativos (NASCIMENTO, 2003 p. 98).

Destaca-se que a área em estudo possui grande declividade, de acordo com os dados de elevação obtidos através do software Google Earth Pro e das observações in loco, o que contribui para o escoamento concentrado da água, resultando no surgimento de processos erosivos, como estes observados nas imagens (figura 4). Pode-se verificar a formação de processos erosivos perto das residências, aumentando os riscos de deslizamento e movimentos de massa. Observa-se também a falta de um sistema de drenagem pluvial o que gera problemas como inundações e alagamentos. Aliado a essa falta de galerias pluviais, o aumento de arruamentos com capa asfáltica, fruto da expansão urbana, acarreta em impermeabilização do solo e concentração de enxurradas.

Figura 4 - Ponto A do trecho do Córrego Catingueiro, processos erosivos em B e D e fissuras em muro construído na área de proteção do córrego em $\mathrm{C}$.
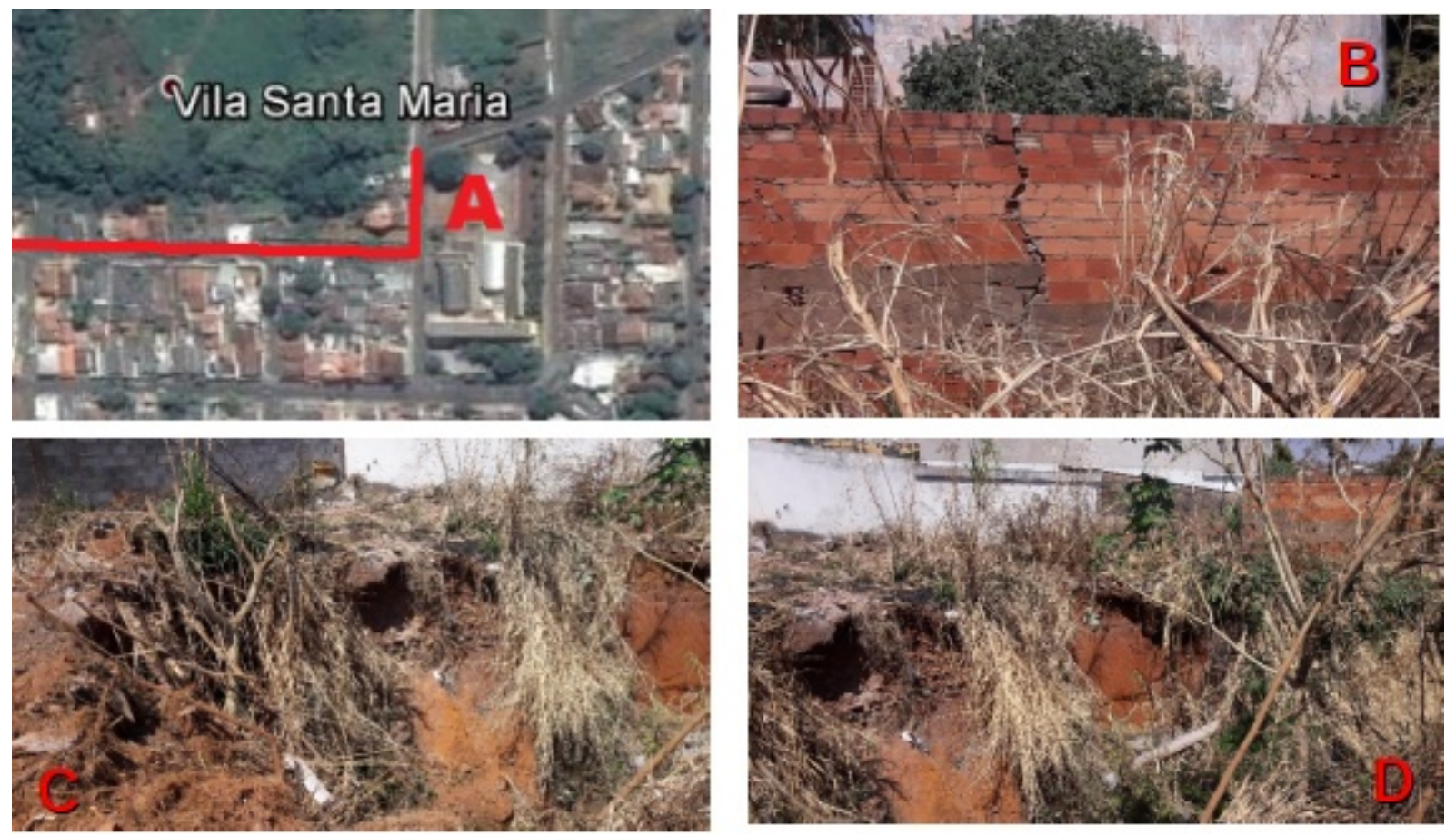

Fonte: Google Earth (2017), registros fotográficos dos autores (2018)

Com essas condições, as águas provenientes das precipitações ganham maior velocidade e chegam até o Córrego Catingueiro de forma violenta, causando erosões marginais, solapamentos e assoreamento, além de entulhamento por resíduos urbanos. 
Enfatiza-se a falta de planejamento urbano, pois, é um grande problema de muitas cidades brasileiras, como em Anápolis. A crescente expansão urbana não foi acompanhada de políticas públicas que se preocupassem com a infraestrutura urbana necessária para que não houvesse esses impactos ambientais. Dessa maneira, fica evidente a necessidade de aumento de investimentos públicos em obras de drenagem tanto pluvial como fluvial.

A capa asfáltica é a responsável por levar as águas pluviais, através das inclinações longitudinais e transversais, às sarjetas que completam o sistema de drenagem superficial de uma via pública. Esse escoamento superficial necessita de pontos de coleta (bocas de lobo) para que leve a água para a rede de drenagem pluvial profunda, que por sua vez levará a uma estrutura de lançamento final no Córrego Catingueiro.

Verifica-se na figura 5 o local analisado e a seta amarela indica o sentido do escoamento superficial concentrado da água evidenciado na Rua Professor Salvador dos Santos, na Vila Brasil (figura 5B). A falta de um sistema de drenagem resulta em alagamentos em períodos chuvosos, bem como favorece os riscos de deslizamento nas proximidades das residências, visto a ausência de mata ciliar e ao processo de ocupação irregular. Outro aspecto demonstrado na figura $5 \mathrm{C}$ é a quantidade de entulhos dispostos de maneira inadequada na área de inundação do Córrego Catingueiro.

\section{Figura 5 - Ponto B do trecho do Córrego Catingueiro, depósito irregular de resíduos em B e rua} sem captação para drenagem de águas pluviais em $\mathrm{C}$.
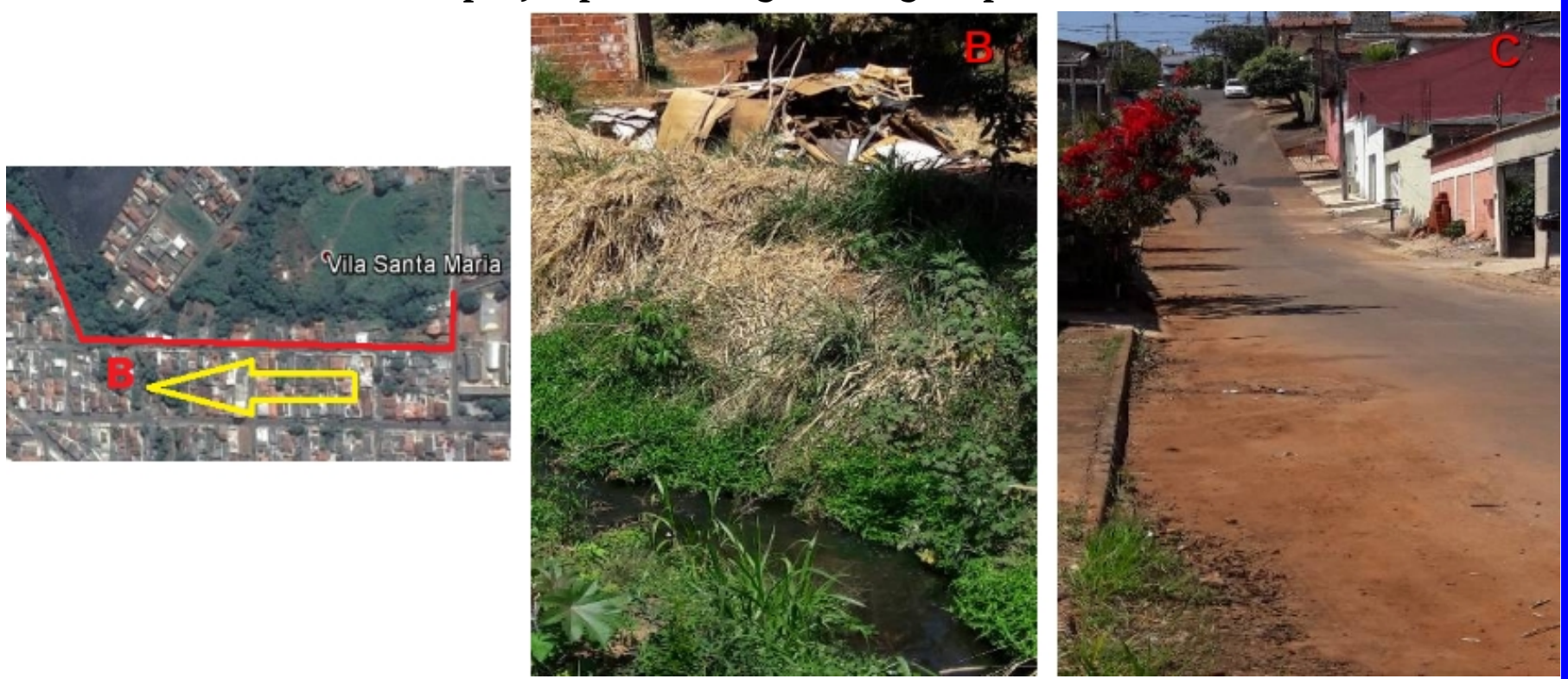

Fonte: Google Earth (2017), registros fotográficos dos autores (2017).

De acordo com Matos (2010), a urbanização altera o ciclo hidrológico, tendo em vista que proporciona aumento da impermeabilização do solo e assim a redução da infiltração de água tendo como implicação o aumento do deflúvio. Outra consequência é proporcionar o aumento da erosão, proporcionando o carreamento de resíduos para os cursos d'água, aumentando o assoreamento de corpos hídricos e consequentemente maximizando o risco de enchentes.

Nos grandes centros urbanos têm-se muitos problemas com as enchentes. A população, principalmente das áreas ribeirinhas, fica exposta a vários problemas durante o período chuvoso, que é quando isso se agrava. Isso é mostrado sempre nos noticiários em períodos chuvosos (figura 6). 


\section{Figura 6 - Anápolis em período chuvoso}

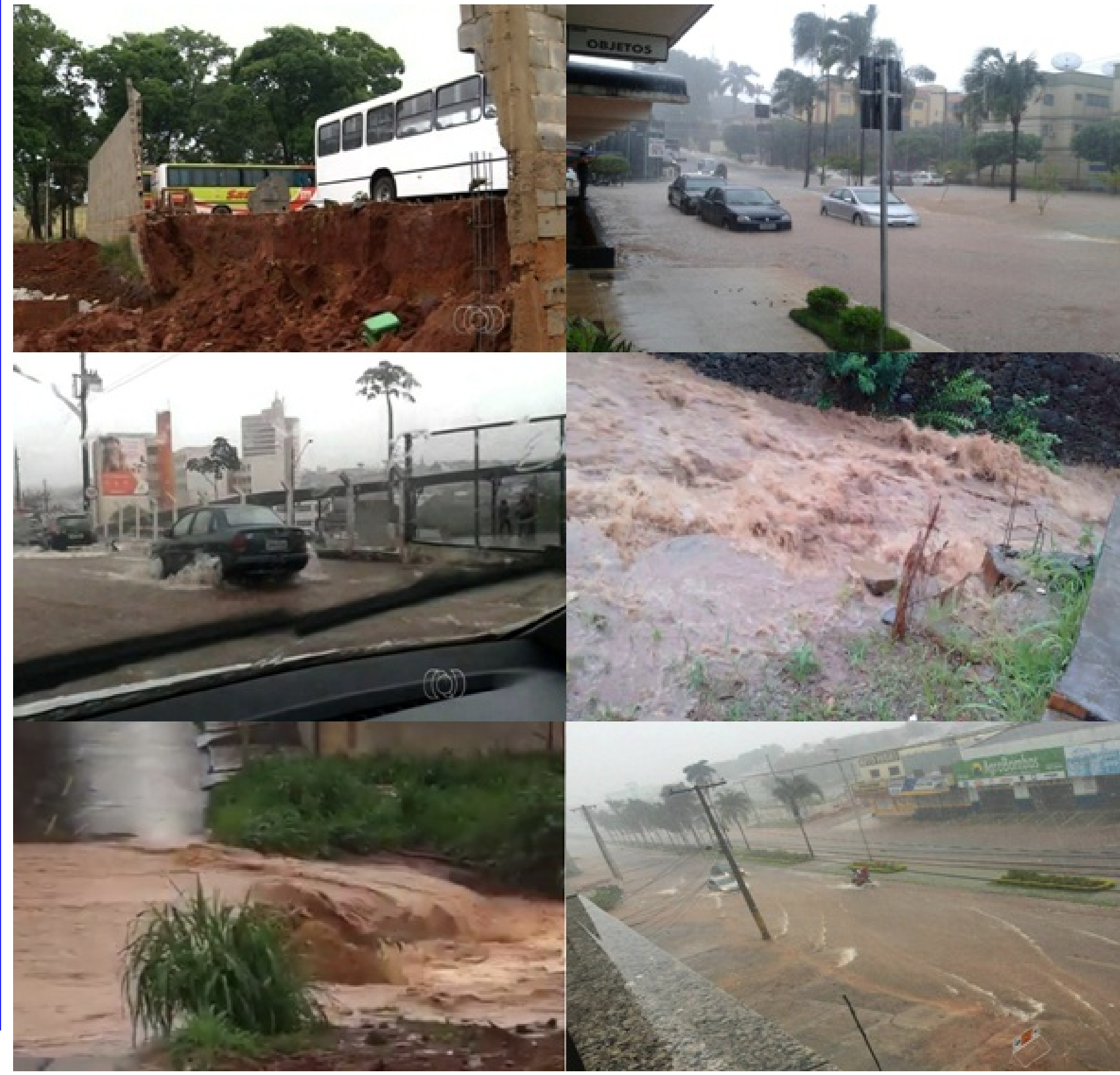

Fonte: Imagens capturadas no Google (2018)

A Rua São Francisco de Assis em destaque na figura 7B, localizada na margem esquerda do Córrego Catingueiro possui uma declividade acentuada. O local apresenta cotas altimétricas elevadas, acima de 960 metros e declives superiores a 20\%. Observa-se na margem direita a presença de entulhos da construção civil, que são dispostos de maneira inadequada. Esse fato contribui para o carreamento de resíduos para o curso ocasionando assoreamento, entulhamento e mudanças na área de inundação do corpo hídrico.

No que se refere aos solos, ocorre à presença dos tipos Latossolo Vermelho (topo do relevo) e dos Argissolos, Cambissolos e Neossolos Litólicos (borda e encosta escarpada do relevo). A associação desses aspectos físicos com os desmatamentos promovidos pela expansão urbana desordenada favorece a aceleração dos processos erosivos. Uma região com essas características físicas deveria compatibilizar o arruamento e divisão das quadras com as curvas de nível do terreno, bem como incorporar obras de drenagem adequadas à capacidade do fluxo das águas pluviais (NASCIMENTO, 2003 p. 102 e 103). 
Figura 7 - Ponto C do trecho do Córrego Catingueiro (imagem A), depósito irregular de resíduos em $\mathrm{B}$ e $\mathrm{C}$.

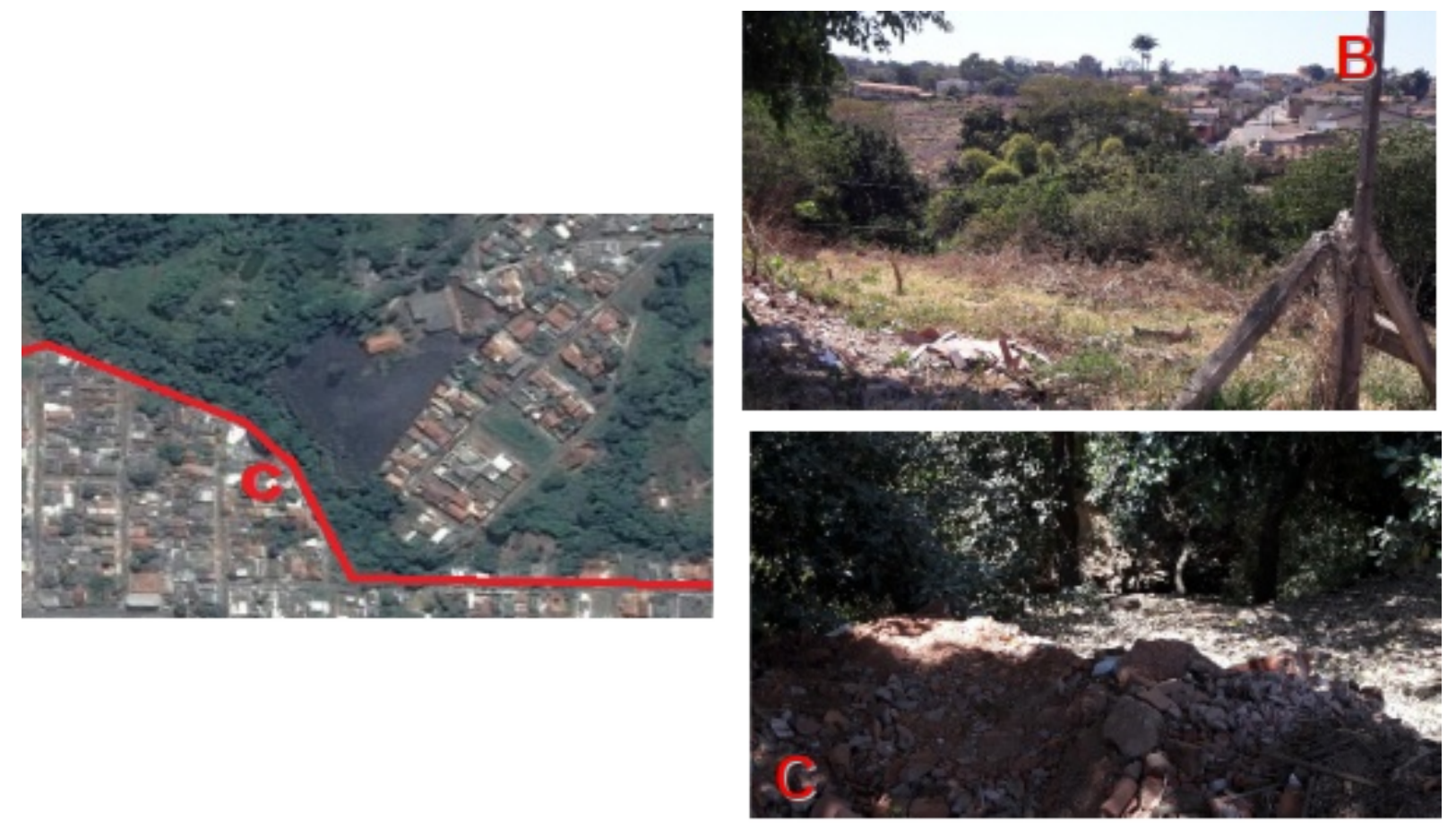

Fonte: Google Earth (2017), registros fotográficos dos autores (2017)

$\mathrm{Na}$ visita realizada na área evidenciada pela figura 7, nota-se principalmente que os moradores de áreas de risco, os que estão junto às margens do Córrego Catingueiro não foram contemplados com a rede de coleta de esgoto doméstico, nem com outras infraestruturas, sendo os dejetos lançados in natura diretamente no referido córrego.

Segundo Zamparoni (2014), àqueles que não têm acesso a bens e serviços públicos, assim como segurança, justiça social e a cidadania, se faz necessária, pois tais pessoas estão vulneráveis socialmente, ou seja, excluídas de compor a malha de habitação segura, de ter acesso ao saneamento básico, à educação, aos equipamentos culturais (teatro e cinema) e outras benfeitorias que são direitos de todos os cidadãos.

O governo de qualquer esfera ao assumir o papel de gestor urbano, tem a capacidade de reverter essa condição de vida nas periferias, fazendo do planejamento uma ferramenta de gestão que pode melhorar os serviços urbanos, além de permitir com que cada vez mais pessoas tenham acessos a esses recursos e infraestruturas.

Segundo Alheiros (2003), os territórios localizados nas áreas de planícies possuem elevado valor e interesse imobiliários, ficando as áreas de morros como espaço territorial de expansão para moradia do segmento mais pobre da população.

Sendo assim, as camadas sociais menos favorecidas, nas proximidades recebem as piores áreas para construir suas casas e viver. Isso fica evidenciado na figura $8 \mathrm{C}$, pois, apesar da proximidade com o canal fluvial, o morador utilizou-se de um aterro e construiu um muro que, invariavelmente, está fadado ao deslizamento e, ao consequente desmoronamento. 
Figura 8 - Ponto D do trecho do Córrego Catingueiro (imagem A), depósito irregular de resíduos em $\mathrm{B}$, aterro irregular na margem do córrego e proximidade da construção com 0 leito do córrego em C e D.
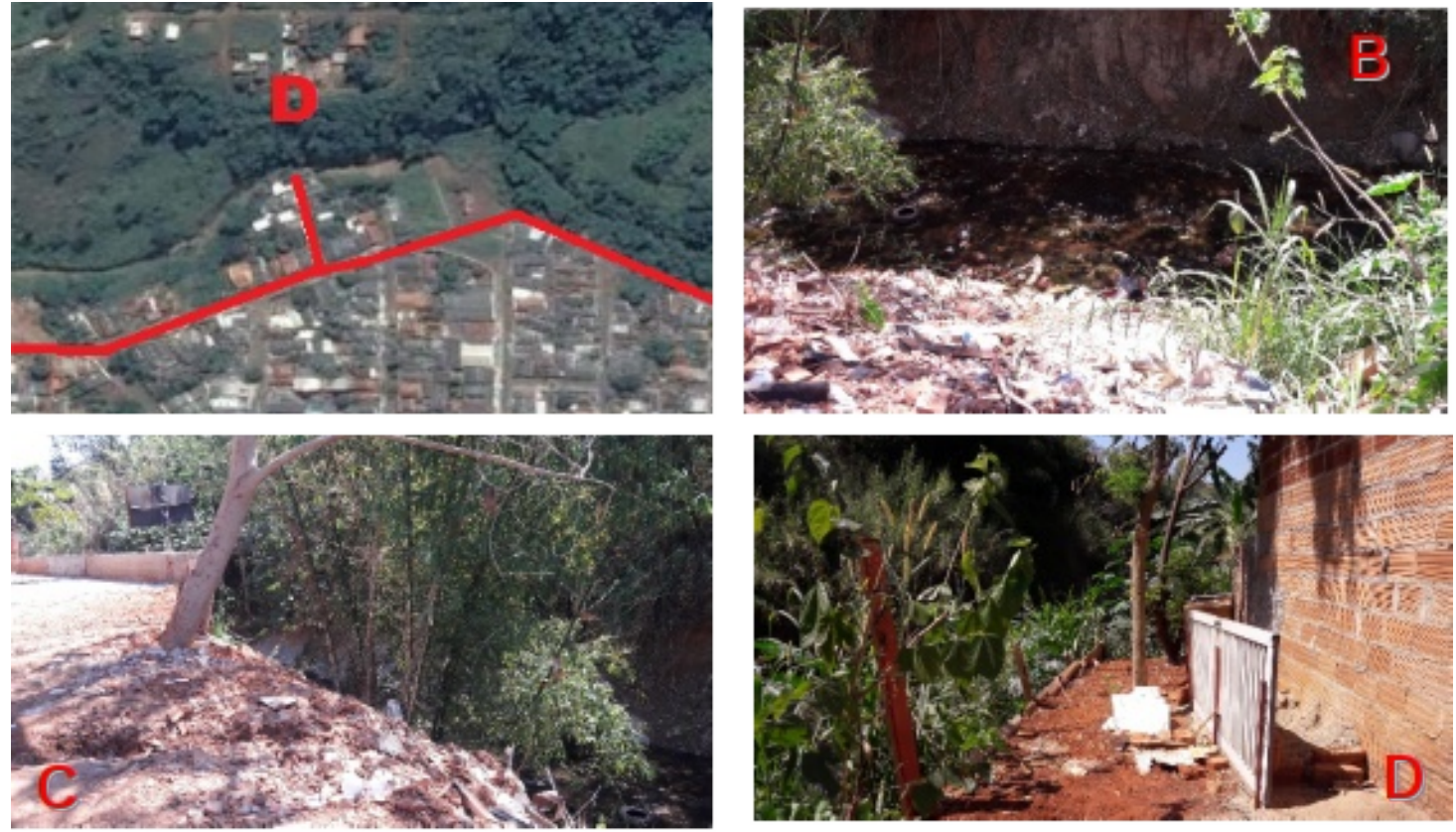

Fonte: Google Earth (2017), registros fotográficos dos autores (2017)

As extrações de terra e de argila realizadas por olarias se estendem em áreas alagadiças junto ao córrego citado e no trecho da Vila Fabril. As escavações realizadas expõem o solo à ação das chuvas que contribuem para o soterramento dos fragmentos de vegetação ciliar, de olhos d'água e de partes do curso hídrico (figuras $9 \mathrm{~b}$ e 9c). No entanto essas olarias/cerâmicas estão encontrando dificuldades em realizar as renovações das licenças ambientais, conforme apresentado na reportagem do Jornal Estado de Goiás, em 03 de julho de 2017. Segue:

O problema começou após a criação da Área de Proteção Ambiental (APA) do Ribeirão João Leite, em 2010. Desse período até hoje, as empresas estão com muita dificuldade para renovar as licenças ambientais para a extração de argila. Só em Anápolis, já foram fechadas 11 cerâmicas, aumentando o número de desempregados no município. Segundo o presidente, Donizete Ferreira, a associação tem um projeto na área ambiental, que tem como objetivo buscar recursos para adquirir uma região e que seja construído um viveiro. A expectativa é conseguir uma parceria com os municípios que estão na região da APA do Ribeirão João Leite (Jornal Estado de Goiás, em 03 de julho de 2017).

Figura 9 - Ponto E do trecho do Córrego Catingueiro (imagem A), atividade de extração para olarias na margem do córrego em B e C.
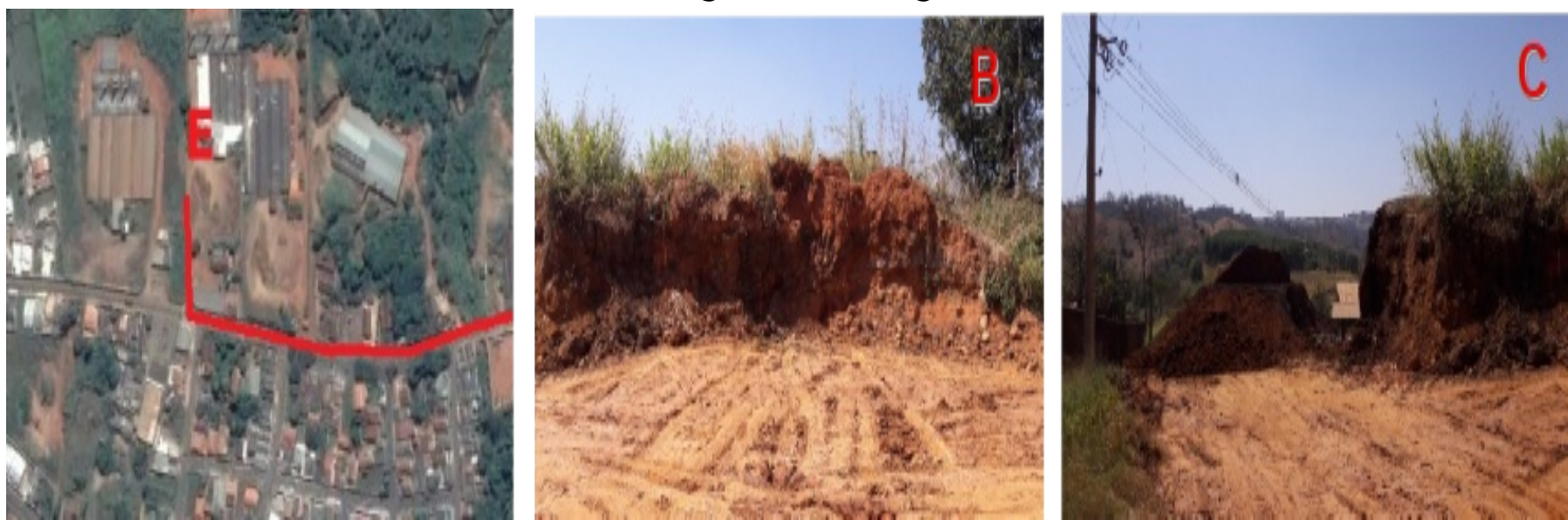

Fonte: Google Earth (2017), registros fotográficos dos autores (2017). 
A APA - Área de Proteção Ambiental do Ribeirão João Leite foi criada pelo Decreto Estadual n 5.704, de 27 de dezembro de 2002 e tem como abrangência os municípios Goiânia, Terezópolis de Goiás, Goianápolis, Nerópolis, Anápolis, Campo Limpo de Goiás e Ouro Verde de Goiás. O plano de manejo foi aprovado pela portaria $n^{\circ}$ 8/2010 proposta pela SEMARH - antiga Secretaria do Meio Ambiente e Recursos Hídricos de Goiás. Os objetivos dessa proposta são:

\begin{abstract}
Proteger os recursos hídricos da bacia hidrográfica do Ribeirão João Leite; assegurar condições para o uso do solo compatíveis com a preservação dos recursos hídricos; conciliar as atividades econômicas e a preservação ambiental; proteger os remanescentes do bioma cerrado; melhorar a qualidade de vida da população local por meio de orientação e do disciplinamento das atividades econômicas; disciplinar o turismo ecológico e fomentar a educação ambiental (GOIÁS, 2002 e 2010).
\end{abstract}

Nas figuras 10A evidencia o trecho analisado e a 10B a rua sem captação para drenagem das águas pluviais. Verificou-se também que a destinação de resíduos em regiões próximas aos espelhos d'água urbanos é recorrente. Podem-se perceber aqui duas situações que, apesar de distintas, contribuem para tal fato: a falta e/ou ineficiente coleta de resíduos e rejeitos na área e a cultura dos moradores em jogar o seu resíduo próximo aos córregos. Na figura $10 \mathrm{C}$ podemos perceber um bueiro celular que é uma estrutura de concreto armado destinada a fazer a transição da água do córrego sob a pavimentação.

Observa-se na figura 10d a enorme quantidade de resíduos nas adjacências do córrego. Essa quantidade de entulho pode facilmente obstruir os canais do bueiro celular, ocasionando a fadiga da estrutura que não foi dimensionada para tal, podendo inclusive levá-la ao colapso.

Figura 10 - Ponto F do trecho do Córrego Catingueiro (imagem A), rua sem captação para drenagem de águas pluviais em $\mathrm{B}$, bueiro celular de concreto e situação do leito do córrego em C, deposição de resíduos em margem de córrego em $D$.
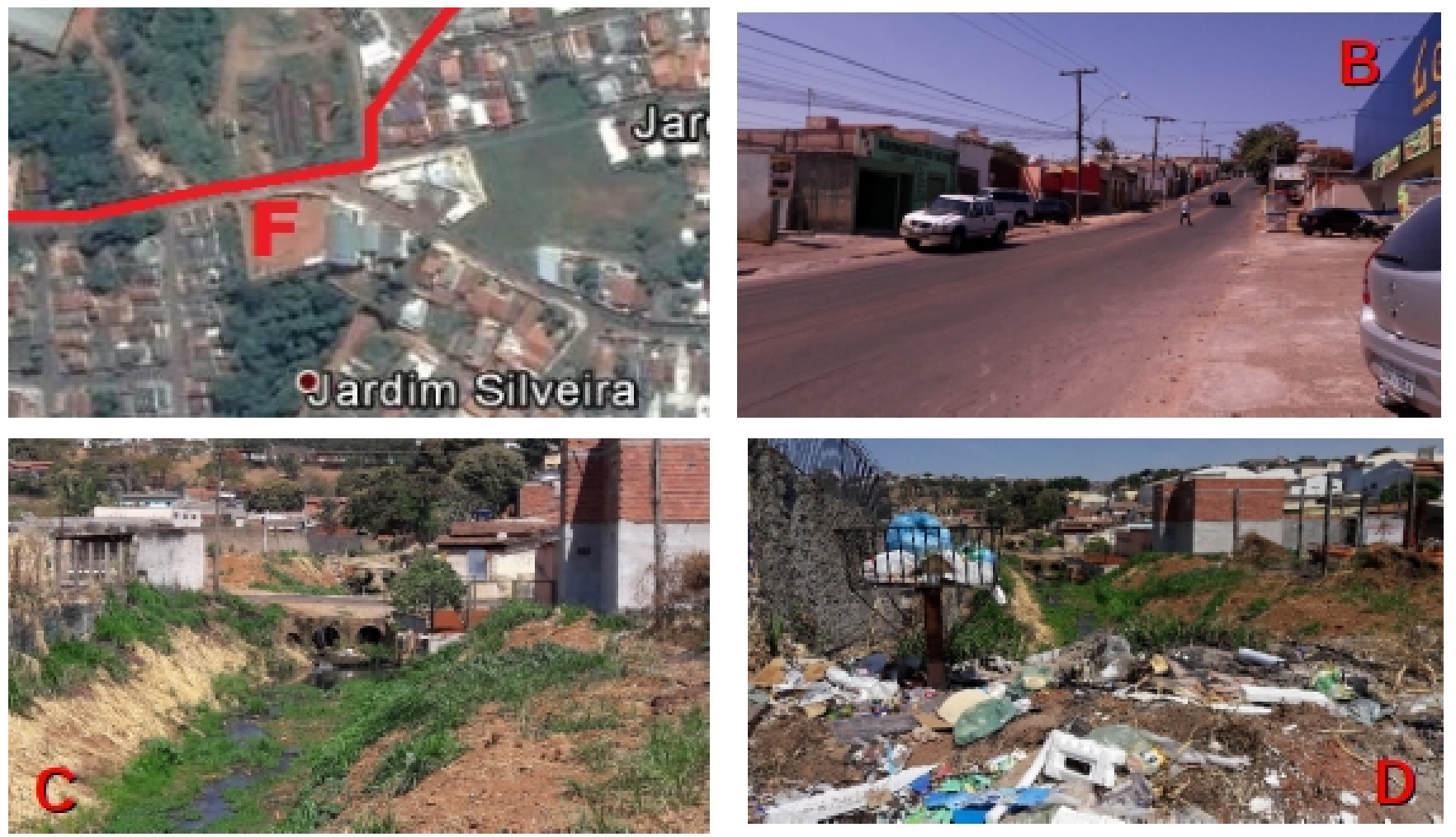

Fonte: Google Earth (2017), registros fotográficos dos autores (2017) 
Adorno (2007) salienta que desde os tempos mais remotos o homem costuma lançar seus detritos nos cursos d'água, porém em pequenas quantidades a natureza consegue realizar a sua autorecomposição, já que os rios, lagos e oceanos têm considerável poder de depuração. Com a industrialização, a situação começou a sofrer alterações. O volume de detritos despejados nas águas tornou-se cada vez maior, superando a capacidade de purificação dos rios e oceanos, que é limitada. Além disso, passou a ser despejado na água elementos que não são biodegradáveis, ou seja, não são decompostos pela natureza. Tais elementos, por exemplo, os plásticos, a maioria dos detergentes e os pesticidas, vão se acumulando nos rios, lagos e oceanos, diminuindo a capacidade de retenção de oxigênio das águas e, consequentemente, prejudicando a vida aquática.

As águas são fonte de vida, mas apesar do grau de importância deste recurso, a vida urbana tem se ocupado em diminuir sua qualidade e quantidade sem a devida preocupação com este recurso que a natureza disponibiliza, mas que não é inesgotável, segundo Adorno (2007).

Durante o percurso realizado, pode-se destacar a ocorrência de diversos impactos ambientais e problemas urbanos (quadro 2).

\section{Quadro 2 - Impactos ambientais e problemas urbanos}

\begin{tabular}{|l|l|}
\hline Aterro de área erodida & Nascentes aterradas \\
\hline Central de entulho & Trechos de assoreamento \\
\hline Trechos de ausência de mata ciliar & Trechos de água com poluição aparente \\
\hline Boçoroca aterrada & Bairros sem rede de esgoto \\
\hline Sulcos e ravinas & Áreas de extração \\
\hline Solo degradado ou exposto & Solapamento de margens \\
\hline
\end{tabular}

Fonte: Nascimento (2003), acréscimos realizados pelos autores (2017)

Esses impactos foram relatados nos estudos de Nascimento (2003) e percebe-se que a situação ainda continua presente na atualidade, sendo que em alguns locais com um grau de agravamento mais acentuado. Esse fato evidencia a necessidade de envolvimento de vários setores da sociedade, tais como o poder público, comunidade, empresários, no processo de recuperação do local. Uma busca na tentativa de restabelecer as relações entre o homem e a natureza, diluídas na trajetória histórica e visíveis nas paisagens cinzentas da cidade.

Verifica-se que essas inquietações buscam provocar ainda mais as discussões acerca do tema, bem como, fomentar a necessidade de vislumbrar a atuação de diversos profissionais interligados e pensar o urbano como um locus de planejamento e ação de alternativas sustentáveis.

\section{CONSIDERAÇÕES FINAIS}

Através do estudo realizado, verificou-se que esse trecho do Córrego Catingueiro ainda está sendo impactado em decorrência da expansão urbana desordenada, da ineficiência de políticas públicas e da falta de educação ambiental da comunidade.

Os principais impactos detectados in situ foram nascentes aterradas, descarte irregular de entulhos, processos erosivos iniciais e avançados, solo degradado, compactado, solapamento de margens, áreas de extração irregular de argilas para as olarias e cerâmicas, trechos com ausência de 
mata ciliar, trechos assoreados, trechos com lançamento clandestino de dejetos diversos, bairros sem rede de esgoto e depósitos irregulares de lixo em terrenos baldios e outros. Esses aspectos ainda podem ser observados no local e nas adjacências à montante e à jusante, dessa maneira, continuam contribuindo para a redução da qualidade e quantidade dessas águas.

No quesito legal, verifica-se nas esferas municipal, estadual e federal, todo o amparo para restrição do uso irregular e expansão de novos empreendimentos, bem como incentiva a recuperação desse ambiente através do Plano de Manejo aprovado pela portaria ํㅡㅇ 8/2010, devido ao local integrar a APA do Ribeirão João Leite.

Sendo assim, torna-se imprescindível que medidas estratégicas de recuperação das nascentes e afluentes da sub-bacia do Córrego Catingueiro sejam implementadas e desenvolvidas e que esse aspecto decorre das parcerias entre o poder público, centros de pesquisa e comunidade. Somente através desses procedimentos, os projetos de recuperação ambiental e monitoramento da área vão se tornar eficazes.

\section{REFERÊNCIAS BIBLIOGRÁFICAS}

ADORNO, M. L. G. Anápolis, um estudo da evolução urbana e impactos ambientais sobre os recursos hídricos: estudo de caso: Córrego das Antas. 2007. 237f. Dissertação (Mestrado em Arquitetura e Urbanismo) - Programa de Pós-Graduação em Arquitetura e Urbanismo, Universidade de Brasília, Brasília, 2007.

ALHEIROS, M. M. Riscos de escorregamentos na região metropolitana do Recife. 1998. 135 f. Tese (Doutorado em Geologia) - Programa de Pós-Graduação em Geologia, Universidade Federal da Bahia, Salvador, 1998.

ANÁPOLIS. Lei complementar n. 001, de 15 de Fevereiro de 2016 (Plano Diretor Participativo do Município de Anápolis). Anápolis: PMA, 2016.

ANÁPOLIS. Redes hídricas. Anápolis: PMA, 2005.

BRASIL. Lei n. 12.651, de 25 de maio de 2012 (Proteção da Vegetação Nativa). Brasília: Senado Federal, 2012.

FELIPPE, M. F.; MAGALHAES JÚNIOR, A. P. Consequências da ocupação urbana na dinâmica das nascentes em Belo Horizonte - MG. Belo Horizonte: ABEP, 2009.

GOIÁS. Decreto estadual n. 5.704, de 27 de dezembro de 2002 (APA - Área de Proteção Ambiental do Ribeirão João Leite). Goiânia: SEMARH, 2002.

GOIÁS. Portaria n. 8, de 2010 (Plano de Manejo da APA - Área de Proteção Ambiental do Ribeirão João Leite). Goiânia: SEMARH, 2010.

JORNAL DO ESTADO DE GOIÁS. Cerâmicas da Vila Fabril vivem crise e podem deixar de existir. 2017. Disponível em: <http://www.jornalestadodegoias.com.br/2017/07/03/ceramicas-da-vila-fabrilvivem-crise-e-podem-deixar-de-existir/>. Acesso em: 19 ago. 2017.

LACERDA, H. Mapeamento geomorfológico como subsídio ao controle preventino da erosão urbana em Anápolis - GO. In: CONGRESSO BRASILEIRO DE GEOLOGIA DE ENGENHARIA E AMBIENTAL, XI, 2005. Anais... Florianópolis: ABGE, 2005. p. 679-692.

MARTINS, S. V. Recuperação de matas ciliares. Viçosa: Fácil, 2014.

MATOS, A. T. Poluição ambiental: impactos no meio físico. Viçosa: UFV, 2010.

NASCIMENTO, A. S. Impactos ambientais e expansão urbana nas cabeceiras de drenagem do Córrego Catingueiro em Anápolis/GO. 2003. 153 f. Dissertação (Mestrado em Geografia) - Instituto de Estudos Socioambientais, Universidade Federal de Goiás, Goiânia, 2003.

NOGUEIRA, L. L. F.; ESPINDOLA, G. M.; CARNEIRO, E. L. N. C. Análise da ocupação urbana na zona centronorte de Teresina: considerações sobre a Região do Encontro dos Rios. In: Revista Equador, Teresina, $\mathrm{v}$. 5, n. 3, p. 25-42, 2016.

POLETO, C. Introdução ao gerenciamento ambiental. Rio de Janeiro: Interciência, 2010.

TUCCI, C. E. M. Águas urbanas. In: Estudos Avançados, São Paulo, v. 22, n. 63, p. 97-112, 2008.

TUNDISI, J. G. Recursos hídricos no futuro: problemas e soluções. In: Estudos Avançados, São Paulo, v. 22, n. 63, p. 07-16, 2008.

ZAMPARONI, C. A. G. P. Áreas de riscos, mobilizada urbana, vulnerabilidade e o poder público em Cuiabá / MT. Cuiabá: UFMT, 2014. 